\title{
Dietary intakes and diet quality according to levels of organic food consumption by French adults: cross-sectional findings from the NutriNet-Santé Cohort Study
}

\author{
Julia Baudry ${ }^{1, *}$, Benjamin Allès ${ }^{1}$, Sandrine Péneau ${ }^{1}$, Mathilde Touvier ${ }^{1}$, Caroline Méjean ${ }^{1}$, \\ Serge Hercberg ${ }^{1,2}$, Pilar Galan ${ }^{1}$, Denis Lairon ${ }^{3}$ and Emmanuelle Kesse-Guyot ${ }^{1}$ \\ ${ }^{1}$ COMUE Sorbonne-Paris-Cité, Equipe de Recherche en Epidémiologie Nutritionnelle (EREN), Centre \\ d'Epidémiologie et Statistiques Paris Cité, Institut National de la Santé et de la Recherche Médicale (INSERM, \\ U1 153), Institut National de la Recherche Agronomique (INRA, U1 125), Conservatoire National des Arts et Métiers \\ (CNAM), Université Paris 13, F-93017 Bobigny, France: ${ }^{2}$ Département de Santé Publique, Hôpital Avicenne, \\ Bobigny, France: ${ }^{3}$ Nutrition, Obésité et Risque Thrombotique (NORT), Institut National de la Santé et de la Recherche \\ Médicale (INSERM), UMR S 1062, Institut National de la Recherche Agronomique (INRA) 1260, \\ Aix Marseille Université, Marseille, France
}

Submitted 2 June 2016: Final revision received 3 August 2016: Accepted 5 September 2016: First published online 12 0ctober 2016

\begin{abstract}
Objective: We aimed to assess dietary profiles of adults from the NutriNet-Santé cohort according to different levels of organic food consumption using detailed self-reported data on organic food intakes.

Design: Food intakes were obtained using an organic food frequency questionnaire (Org-FFQ). The participants were ranked into five groups (quintiles, Q) according to the proportion of organic foods in their diet. To determine diet quality, two scores were computed reflecting adherence to food-based recommendations (mPNNS-GS) and the probability of adequate nutrient intake (PANDiet). Relationships between levels of organic food consumption and dietary characteristics were assessed using multivariable-adjusted ANCOVA models.

Setting: The NutriNet-Santé Study.

Subjects: French adults from the NutriNet-Santé Study ( $n$ 28 245).

Results: Intakes of foods of plant origin increased along with the contribution of organic foods to the diet while a reverse trend was identified for dairy products, cookies and soda ( $P$-trend $<0.0001)$. The diet quality scores increased from Q1 (mPNNS-GS, 7.89 (se 0.02); PANDiet: 63.04 (sE 0.11)) to Q5 (mPNNS-GS, 8.78 (SE 0.02); PANDiet, 69.37 (sE 0.10)). Overall, high organic food consumers exhibited better diet quality, although intermediate organic food consumers showed better adherence to specific nutritional recommendations related to animal products.

Conclusions: The study provides new insights into the understanding of organic food consumption as a part of a healthy diet and sheds some light on the dietary profiles of different categories of organic food consumers. These results underline strong dietary behaviour correlates associated with organic food consumption that should be controlled for in future aetiological studies on organic foods and health.
\end{abstract}

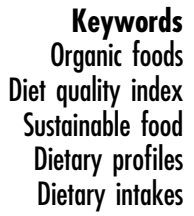

One of the key challenges of the current food systems is both to meet the nutritional requirements of a growing population and to adopt sustainable production practices ${ }^{(1)}$. In this context, organic agriculture, defined in 2015 by the International Federation of Organic Agriculture Movements as 'a production system that sustains the health of soils, ecosystems and people', is often seen as a spearhead for a transition towards more sustainable food production ${ }^{(2)}$. Notably, organic agriculture has been promoted by public policies in France since 1981 through an agriculture law that officially acknowledged the principles of organic agriculture and in Europe since 1991, through regulations establishing the legal framework for agricultural products and foodstuffs obtained organically. the expansion of demand for organic foods in France over the past decades ${ }^{(3,4)}$ is also largely driven by consumers' beliefs of the health benefits of organic foods ${ }^{(5-9)}$. Consumers are becoming more and more demanding with regard to the quality and safety of foods, which they want to have high nutritional values and be pesticide free ${ }^{(10)}$. Organic foods are perceived as healthier because of the
In addition to this increased attention of governments, 
absence of pesticide residues ${ }^{(11-14)}$ and more nutritious based on growing evidence for some foodstuffs ${ }^{(12-16)}$, while the studies on the direct health impacts of organic foods are scant and inconsistent ${ }^{(17-23)}$.

As the organic industry continues to gain market share $^{(3)}$, it is therefore crucial from a public health point of view to describe and characterise organic food consumers. A detailed knowledge of organic food consumers' profiles and correlates is an important prerequisite to future aetiological studies on the health impact of organic foods.

Recent studies have described regular organic food consumers as exhibiting an overall healthier lifestyle than non-consumers, as well as having better food choice habits ${ }^{(24-30)}$. However, several of these studies have focused on specific population subgroups such as pregnant women $^{(25,26)}$, or were conducted on small samples ${ }^{(24,29)}$. Thus, comparisons of food habits between organic food consumers and non-consumers based on nutritional intakes of a large population sample of adults are sparse ${ }^{(28,30)}$. In addition, these studies often focused on few categories of organic food. It is essential to consider the intake of numerous food groups among a large sample of subjects in order to cover a wide range of dietary practices. In addition, for research investigating the impact of organic food consumption on health status, it is also crucial to discriminate dedicated organic food consumers from those whose intake is only occasional or accidental. Approaches focusing only on consumption frequency do not integrate the quantities of organic foods consumed, while potential health impacts of the type of production are likely to be dependent on the percentage of total foods consumed that is organic or conventional.

In this context, the aim of the present study was to assess dietary intakes and overall diet quality according to different levels of organic food consumption among a large sample of French adults using detailed self-reported data on organic food intake.

\section{Materials and methods}

\section{Study population}

Data were collected from the NutriNet-Santé Study, a large web-based prospective observational cohort of adult volunteers aged 18 years or older, launched in France in May 2009 with a scheduled follow-up of 10 years. The NutriNetSanté Study has been described in detail elsewhere ${ }^{(31)}$.

\section{Data collection}

\section{Sociodemographic data}

At baseline and at each year thereafter, participants filled out self-administered questionnaires using a dedicated website to collect data on sociodemographic and lifestyle characteristics, including sex, age, height, weight, smoking status, physical activity (as measured by the International
Physical Activity Questionnaire ${ }^{(32)}$ ), educational level, household size, marital status, number of children living at home, place of residence and current practices of diet (vegan or vegetarian diets). The baseline questionnaires were pilot-tested and compared against traditional assessment methods ${ }^{(33,34)}$. Income per household unit was calculated using information about household income and composition using the official weighting system by the French National Institute of Statistics and Economics Studies (INSEE) ${ }^{(35)}$.

\section{Organic food frequency questionnaire (Org-FFQ)}

Overall food consumption and the relative share of organic foods in the diet were assessed using a webbased, semi-quantitative, 264-item organic food frequency questionnaire (Org-FFQ) based on a previously validated $\mathrm{FFQ}^{(36)}$. The Org-FFQ has been described elsewhere ${ }^{(37)}$. Participants were asked to report their frequency of consumption over the past year for 264 food and beverage items divided into food group categories. For most food items, to estimate food intake, standard portion sizes were applied in the questionnaire and participants were asked to report their consumption frequency on the basis of how many times they ate the standard portion size proposed (typical household measurements such as teaspoon). For eight of the main food group categories (cheese and vegan cheese; pâté and vegan pâté; fish; meat; butter used on bread; potatoes; starchy foods; vegetables) which are not usually eaten in a predetermined portion size, the questionnaire included sets of coloured validated photographs ${ }^{(38)}$. Participants were asked to choose among three photographs showing different portion sizes. The frequency of consumption referred to usual consumption over the past year on an increasing scale including yearly, monthly, weekly or daily units and participants were asked to provide only one answer. To estimate the intake of each food item in grams, standard portion sizes or portion sizes corresponding to the photographs were multiplied by the reported frequencies. Nutrient intakes were estimated using a food composition table developed for the 264 food items of the Org-FFQ based on the ad hoc NutriNet-Santé composition table that originally includes more than 2100 foods $^{(39)}$. As a unique food composition database has been used for nutrient calculations, possible differences for contents in organic $v$. conventional foods reported in literature have not been taken into account (e.g. differences in contents of antioxidant compounds or $n-3$ fatty acids ${ }^{(14-16)}$ ). For mixed dishes, standard recipes were applied.

To determine the proportion of the intake that was from organic origin, for each food item except for water and sweetener products that do not exist in organic form, participants were asked to estimate how often the item came from organic source through a 5-point ordinal scale ranging from 'never' to 'always'. In order to estimate the organic intake of each food item, a weight of $0,0 \cdot 25,0 \cdot 50$, 0.75 and 1 was respectively applied to the following 
frequency categories: 'never', 'rarely', half the time', 'often' and 'always'.

\section{Assessment of diet quality}

To analyse the level of compliance with the French nutritional recommendations, two a priori dietary scores were computed reflecting the dietary components of adherence to French nutritional guidelines: (i) the modified Programme National Nutrition Santé Guidelines Score (mPNNS-GS) ${ }^{(40)}$; and (ii) the probability of adequate nutrient intake (PANDiet) ${ }^{(41)}$ (Fig. 1).

The PNNS-GS has been described elsewhere ${ }^{(40)}$. Briefly, the original score includes thirteen components: eight refer to food serving recommendations (fruit and vegetables; starchy foods; wholegrain foods; dairy products; meat, poultry, seafood and eggs; seafood; vegetable fat; non-alcoholic beverages), four refer to moderation in consumption (added fat; salt; sweetened foods; alcohol) and one refers to physical activity. Points are deducted for overconsumption of salt and sweets. Points are also deducted from the total when energy intake exceeds the necessary energy level by more than $5 \%$. In the present study, we computed a modified version of the PNNS-GS (mPNNS-GS) which did not integrate the physical activity component. Additionally, the percentages of participants with adequate intakes for the twelve individual dietary components of the mPNNS-GS were provided.

The PANDiet has also been described elsewhere ${ }^{(41)}$. Briefly, the PANDiet is composed of adequacy probabilities for nutrients grouped into two sub-scores (an adequacy sub-score and a moderation sub-score) using French national nutritional recommendations. In the present study, the following nutrients were selected for computation of the PANDiet: protein, total carbohydrate, total fat, added simple carbohydrates, SFA, PUFA, $n-3$ fatty (a)

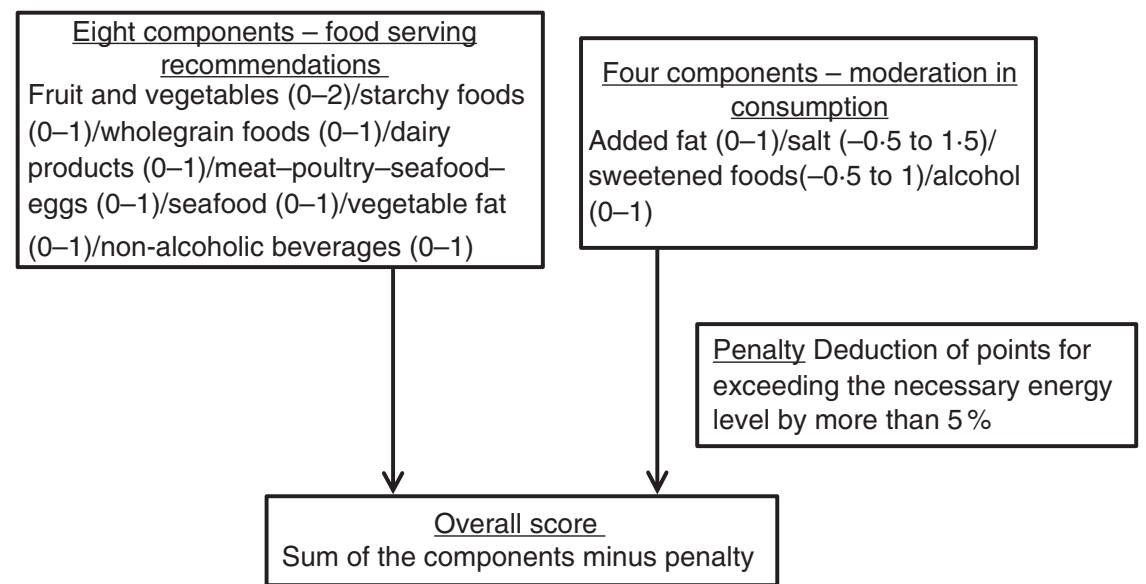

Range: negative scores possible (due to penalties) to 13.5

(b)

\section{Adequacy sub-score \\ Probability* of adequate intake: \\ Protein, total carbohydrate, total fat, PUFA, $n-3$ fatty acids, $n-6$ fatty acids, fibre, vitamins $A, B_{1}, B_{2}, B_{3}, B_{5}, B_{6}, B_{9}$, $\mathrm{B}_{12}, \mathrm{C}, \mathrm{D}$ and $\mathrm{E}, \mathrm{Ca}, \mathrm{Mg}, \mathrm{Zn}, \mathrm{P}, \mathrm{K}, \mathrm{Fe}$, iodine, Se}

*Probabilistic calculation to
estimate the adequacy of the
usual intake of a nutrient:
$F\left(\frac{y-r}{S D_{r}}\right)$
$F:$ probnorm function in SAS
$y$. mean intake
$r$. nutrient reference value
$S D_{r}$ : inter-individual variability

Moderation sub-score

Probability of non-excessive intake: Protein, total carbohydrate, total fat, added simple carbohydrates, SFA, cholesterol, $\mathrm{Na}$

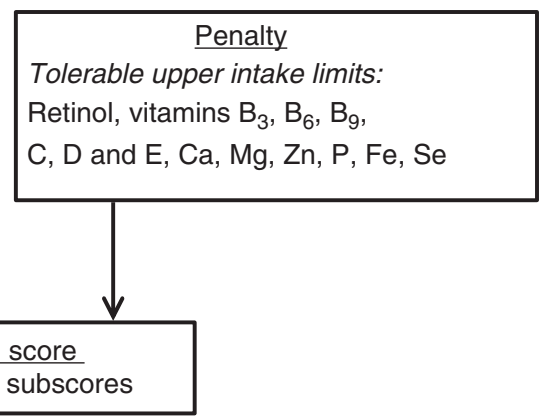

Average of subscores

Fig. 1 Computation of diet quality scores: (a) modified Programme National Nutrition Santé Guidelines Score (mPNNS-GS), reflecting adherence to the French nutritional guidelines ${ }^{(40)}$; (b) PANDiet, reflecting the probability of adequate nutrient intake ${ }^{(41)}$ 
acids, n-6 fatty acids, cholesterol, fibre, vitamins $\mathrm{A}_{1} \mathrm{~B}_{1}$ (thiamin), $\mathrm{B}_{2}$ (riboflavin), $\mathrm{B}_{3}$ (niacin), $\mathrm{B}_{5}$ (pantothenic acid), $\mathrm{B}_{6}, \mathrm{~B}_{9}$ (folic acid), $\mathrm{B}_{12}, \mathrm{C}, \mathrm{D}$ and $\mathrm{E}, \mathrm{Ca}, \mathrm{Mg}, \mathrm{Zn}, \mathrm{P}, \mathrm{K}$, $\mathrm{Fe}$, iodine, Se and $\mathrm{Na}$.

\section{Statistical analysis}

The Org-FFQ was administered from June to October 2014. Among the 33384 participants who had completed the questionnaire, we excluded those who were under-reporting or over-reporting ( $n$ 2097), who had missing sociodemographic or socio-economic data $(n$ 2320) and who resided in overseas territories ( $n$ 722), therefore leaving 28245 participants (20980 women and 7265 men).

For each sex, a weighting was calculated according to the 2009 national census on age, occupational categories, area of residence, whether or not the household included at least one child ( $<18$ years), marital status and educational level, using the iterative proportional fitting procedure, in order to adjust the percentage of individuals in each stratum to the actual percentage in the French population ${ }^{(42)}$. To identify under-reporting or over-reporting participants, we estimated BMR by the Schofield equations ${ }^{(43)}$ according to sex, age, weight and height collected at enrolment in the study. Energy requirement, accounting for physical activity level and BMR, was compared with energy intake. The ratio of energy intake to energy requirement was calculated and individuals with ratios below or above cut-offs $(0.35$ and 1.93) were excluded.

The level of organic food consumption, defined as the proportion of organic foods in the overall diet, was computed by dividing the total organic food intake $(\mathrm{g} / \mathrm{d})$ by the total food intake excluding water $(\mathrm{g} / \mathrm{d})$. Then, weighted quintiles (Q) of the contribution of organic foods to the diet were estimated and the participants were classified according to the level of organic foods in their diet. Quintiles allowed defining no, occasional, medium, high and very high levels of organic food consumption. Daily consumption of thirty-four food groups and forty-two nutrients was calculated.

We compared the characteristics of respondents to the Org-FFQ and non-respondents using the $\chi^{2}$ test and Student's $t$ test. Overall, participants who completed the Org-FFQ (before weighting) were significantly older (53.20 (sD 14.07) v. 44.62 (SD 14.20) years) and more often men (79v. $74 \%$ ) than those who did not complete the questionnaire (data not shown).

Descriptive characteristics of the sample are presented as means and standard deviations or as numbers and percentages, as appropriate, across quintiles. $P$ values refer to the linear contrast test for continuous variables or the trend $\chi^{2}$ test for categorical variables.

ANCOVA models were performed to identify the associations between dietary intakes, diet quality (mPNNS-GS and PANDiet) and level of organic food intake in the overall diet. Models were adjusted for sex, age and energy intake. Nutrient data were adjusted for total energy intake using the residual method. Data are presented as means with their standard errors for continuous variables. We used Bonferroni correction to adjust for multiple testing. We analysed trends across the five groups and report the $P$ values from the linear contrast. The contributions of organic foods to each food group (ratios with their standard errors) are also provided and were adjusted for age and sex. For categorical variables, the $P$ value refers to trend $\chi^{2}$ tests.

In a supplementary analysis, we estimated the associations between the nutritional quality of the diet (reflected by the mPNNS-GS) and organic food consumption (using the proportion of organic foods in the diet as a continuous variable) stratified for several sociodemographic and lifestyle factors. The mPNNS-GS was used as the dependent variable and models were adjusted for sociodemographic and lifestyle variables. Parameter estimates and 95\% confidence intervals are provided.

Two-sided tests and $P<0.05$ were used for statistical significance. Data management and statistical analyses were performed using the statistical software package SAS version 9.3 .

\section{Results}

\section{Individual characteristics}

Before weighting, $74 \%$ of the study sample was female, $63 \%$ had post-secondary education and the mean age was 53 (sD14) years.

Table 1 presents participant characteristics across quintiles of organic food consumption. Participants in Q1 consumed no or very little organic foods, while in Q5 organic foods made up, on average, $72 \%$ of the diet. Q1 showed the highest proportion of males, while the proportion of young adults (18-25 years) was the highest in Q4 and Q5. A higher level of organic consumption was linked to a lower proportion of individuals with no high-school diploma and of current smokers. The highest proportion of individuals with a high household income was found in Q3 and the lowest was found in Q1. The highest percentage of individuals living in a population-dense urban unit $(>200000$ inhabitants) was found in Q1, while the highest percentage living in a rural community was found in Q4. Individuals in Q5 were more often highly physically active than individuals in the other quintiles. Finally, a higher level of organic food consumption was linked to a higher proportion of vegetarians or vegans.

\section{Food intakes and relative shares of organic foods by level of organic food consumption}

Table 2 provides mean daily intakes of food groups across quintiles of organic food consumption. The intakes of plantbased foods including vegetables, soups, nuts, wholegrain 
Table 1 Sociodemographic and lifestyle characteristics according to the level of organic food consumption by French adults (weighted sample), NutriNet-Santé Study, 2014 (n 28245) ${ }^{*} \dagger$

\begin{tabular}{|c|c|c|c|c|c|c|c|c|c|c|c|}
\hline \multirow[b]{2}{*}{$n$ and $\%$} & \multicolumn{2}{|c|}{ Q1 $(0.00-0.01)$} & \multicolumn{2}{|c|}{ Q2 (0.01-0.09) } & \multicolumn{2}{|c|}{ Q3 (0.09-0.25) } & \multicolumn{2}{|c|}{ Q4 $(0.25-0.49)$} & \multicolumn{2}{|c|}{ Q5 $(0.49-1.00)$} & \multirow[t]{2}{*}{$P$-trend $\ddagger$} \\
\hline & 3484 & $12 \cdot 3$ & 5099 & $18 \cdot 1$ & 6654 & 23.6 & 6244 & $22 \cdot 1$ & 6764 & 23.9 & \\
\hline Weighted $n$ and $\%$ & 5553.7 & $19 \cdot 7$ & $5742 \cdot 8$ & $20 \cdot 3$ & $5627 \cdot 6$ & 19.9 & $5670 \cdot 7$ & $20 \cdot 1$ & $5650 \cdot 1$ & $20 \cdot 0$ & \\
\hline $\begin{array}{l}\text { Proportion of organic food consumption } \\
\text { in the diet§ }\end{array}$ & 0.00 & 0.00 & 0.04 & 0.03 & 0.17 & 0.04 & 0.36 & 0.06 & 0.72 & 0.15 & $<0.0001$ \\
\hline Sex & & & & & & & & & & & $<0.0001$ \\
\hline Female & & \multirow{2}{*}{\multicolumn{2}{|c|}{53.34}} & \multirow{2}{*}{\multicolumn{2}{|c|}{$\begin{array}{l}55.56 \\
44.44\end{array}$}} & \multirow{2}{*}{\multicolumn{2}{|c|}{$55 \cdot 16$}} & \multicolumn{2}{|c|}{55.97} & \\
\hline Male & & & & & & & & & \multicolumn{2}{|c|}{44.03} & \\
\hline Age & \multicolumn{2}{|c|}{$58 \cdot 44$} & & & \multicolumn{2}{|c|}{44.44} & & & & & $<0.0001$ \\
\hline $18-25$ years & \multicolumn{2}{|c|}{7.52} & \multicolumn{2}{|c|}{8.02} & \multicolumn{2}{|c|}{8.04} & \multicolumn{2}{|c|}{17.01} & \multicolumn{2}{|c|}{$15 \cdot 61$} & \\
\hline $25-40$ years & \multicolumn{2}{|c|}{$24 \cdot 13$} & \multicolumn{2}{|c|}{$26 \cdot 48$} & 29.3 & & $19 \cdot 6$ & & $24 \cdot 9$ & & \\
\hline $40-55$ years & 34.3 & & 29.3 & & 24.3 & & $24 \cdot 2$ & & $19 \cdot 9$ & & \\
\hline $55-65$ years & $12 \cdot 8$ & & $16 \cdot 1$ & & $15 \cdot \varepsilon$ & & $16 \cdot 6$ & & 17.5 & & \\
\hline$\geq 65$ years & $21 \cdot 1$ & & 19.9 & & $22 \cdot 4$ & & 22.4 & & 21.8 & & \\
\hline Educational level & & & & & & & & & & & $<0.0001$ \\
\hline$<$ High-school diploma & $70 \cdot 9$ & & $63 . c$ & & $56 \cdot 1$ & & $55 . c$ & & 53.7 & & \\
\hline High-school diploma & 13.8 & & $16 \cdot 1$ & & 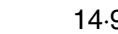 & & 14.5 & & $17 \cdot 3$ & & \\
\hline Post-secondary graduate & $15 \cdot 2$ & & $20 \cdot 7$ & & $28 . c$ & & $30 \cdot 3$ & & 28.9 & & \\
\hline Monthly income per household unit & & & & & & & & & & & $<0.0001$ \\
\hline Refuse to declare & $15 \cdot 7$ & & $13 \cdot 2$ & & $12 \cdot 2$ & & $14 \cdot 4$ & & $16 \cdot 3$ & & \\
\hline $900-1200 €$ & 33.4 & & 26.4 & & 19.9 & & $20 \cdot 1$ & & 21.6 & & \\
\hline $1200-1800 €$ & $26 \cdot 5$ & & $26 \cdot 3$ & & 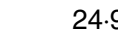 & & $25 \cdot 6$ & & $20 \cdot 9$ & & \\
\hline $1800-2700 €$ & $16 \cdot 9$ & & $21 \cdot 6$ & & $26 \cdot 5$ & & $24 \cdot 2$ & & $27 \cdot 0$ & & \\
\hline$>2700 €$ & $7 \cdot 3$ & & $12 \cdot 2$ & & $16 \cdot 3$ & & $15 \cdot 6$ & & 13.9 & & \\
\hline Location & & & & & & & & & & & $<0.0001$ \\
\hline Rural community & $23 \cdot 0$ & & $24 \cdot 8$ & & $25 \cdot c$ & & $28 \cdot 2$ & & $26 \cdot 0$ & & \\
\hline $\begin{array}{l}\text { Urban unit with a population of } \\
<20000 \text { inhabitants }\end{array}$ & $14 \cdot 8$ & & $15 \cdot c$ & & $18 \cdot 2$ & & $12 \cdot 9$ & & $15 \cdot 0$ & & \\
\hline $\begin{array}{l}\text { Urban unit with a population of } \\
20000-200000 \text { inhabitants }\end{array}$ & $15 \cdot 7$ & & $19 \cdot 1$ & & $15 \cdot 3$ & & $17 \cdot 3$ & & $15 \cdot 0$ & & \\
\hline $\begin{array}{l}\text { Urban unit with a population of } \\
>200000 \text { inhabitants }\end{array}$ & $46 \cdot 2$ & & $40 \cdot 5$ & & 41.4 & & 41.5 & & $43 \cdot 8$ & & \\
\hline Physical activity\|l & & & & & & & & & & & $<0.0001$ \\
\hline Missing & 23.9 & & 17.5 & & 11.5 & & 11.2 & & $9 \cdot 4$ & & \\
\hline Low & 21.5 & & 23.3 & & $23 \cdot 1$ & & 14.4 & & $12 \cdot 3$ & & \\
\hline Medium & $27 \cdot 2$ & & $27 \cdot 6$ & & 35.6 & & 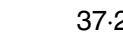 & & 30.8 & & \\
\hline High & $27 \cdot 2$ & & 31.4 & & 29.5 & & $37 \cdot c$ & & 47.4 & & \\
\hline Vegetarian or vegan diet (yes) & 0.2 & & 0.3 & & $2 \cdot 1$ & & $5 \cdot 7$ & & $18 \cdot 1$ & & $<0.0001$ \\
\hline Tobacco status & & & & & & & & & & & $<0.0001$ \\
\hline Never smoker & $46 \cdot 8$ & & $46 \cdot \varepsilon$ & & 44.4 & & $46 \cdot 4$ & & $52 \cdot 3$ & & \\
\hline Former smoker & 34.0 & & 35.9 & & $42 \cdot 4$ & & 40.4 & & 37.8 & & \\
\hline Current smoker & $19 \cdot 1$ & & $17 \cdot 2$ & & $13 \cdot 1$ & & $13 \cdot c$ & & 9.8 & & \\
\hline
\end{tabular}

${ }^{*} \mathrm{Q}$, quintile.

†Values presented are numbers and percentages, means and standard deviations, or percentages, as appropriate.

$\ddagger$ Values based on linear contrast test or trend $x^{2}$ test.

$\S$ Contribution of organic foods to the diet: ratios computed by dividing the total organic food intake ( $\mathrm{g} / \mathrm{d}$ ) by the total food intake excluding water ( $\mathrm{g} / \mathrm{d}$ ).

IAs some questions were optional, data are missing.

products and grains increased across quintiles, while an inverse trend was observed for meat, dairy products, cookies and soda. Dairy and meat substitutes were only marginally consumed by individuals in Q1 while individuals in the other quintiles (notably in Q5) consumed substantial quantities of these products. Individuals in Q4 showed the highest intakes of seafood and eggs while those in Q3 showed the highest intakes of fast foods and alcohol. No linear relationship was found between the intake of sweets and organic food consumption. Supplemental Table 1 (see online supplementary material) provides the relative share of organic foods across quintiles of organic food consumption in the overall diet. The proportion of eggs and poultry that came from organic sources was relatively high even among individuals in Q2 and Q3. Supplemental Table 2 provides detailed information on nutrient intakes across quintiles. Overall, individuals in Q5 showed higher intakes of proteins and lipids of plant origin and of most minerals and vitamins.

\section{Diet quality by level of organic food consumption}

Table 3 shows mean values of the two diet quality scores that reflect adequacy to French food-based and nutrient-based dietary recommendations across quintiles of organic food consumption. Both diet quality scores increased gradually across quintiles. Considering individual food-based recommendations (Table 4), the percentage of individuals meeting the guidelines on plant-based products (fruit and vegetables, bread, cereals, potatoes and legumes) and sweetened foods increased across quintiles while the 
Table 2 Food group intakes by level of organic food consumption in the diet of French adults, NutriNet-Santé Study, $2014(n 28245)^{*}$

\begin{tabular}{|c|c|c|c|c|c|c|c|c|c|c|c|}
\hline \multirow[b]{3}{*}{ Food group (g/d) } & \multirow{2}{*}{\multicolumn{2}{|c|}{$\frac{\text { Q1 }(0.00-0.01)}{\text { Total intake† }}$}} & \multirow{2}{*}{\multicolumn{2}{|c|}{$\frac{\text { Q2 (0.01-0.09) }}{\text { Total intake } \dagger}$}} & \multirow{2}{*}{\multicolumn{2}{|c|}{$\frac{\text { Q3 }(0.09-0.25)}{\text { Total intake† }}$}} & \multirow{2}{*}{\multicolumn{2}{|c|}{$\frac{\text { Q4 (0.25-0.49) }}{\text { Total intake } †}$}} & \multirow{2}{*}{\multicolumn{2}{|c|}{$\frac{\text { Q5 }(0.49-1.00)}{\text { Total intake† }}$}} & \multirow[b]{3}{*}{$P$-trend $f$} \\
\hline & & & & & & & & & & & \\
\hline & Mean & $\mathrm{SE}$ & Mean & SE & Mean & $\mathrm{SE}$ & Mean & $\mathrm{SE}$ & Mean & SE & \\
\hline Vegetables & $222 \cdot 7$ & $2 \cdot 6$ & 223.5 & $2 \cdot 6$ & 229.9 & $2 \cdot 6$ & 249.5 & 2.5 & 359.5 & 2.5 & $<0.0001$ \\
\hline Soups & 57.4 & 1.3 & 57.5 & 1.3 & $59 \cdot 2$ & 1.3 & 72.9 & 1.3 & 83.8 & 1.3 & $<0.0001$ \\
\hline Fruit & 244.0 & 3.9 & 274.3 & 3.9 & $212 \cdot 8$ & 3.9 & 251.4 & 3.8 & 330.2 & 3.8 & $<0.0001$ \\
\hline Fruit juice & 81.2 & 1.6 & 78.8 & 1.5 & 83.5 & 1.6 & 94.3 & 1.5 & $96 \cdot 3$ & 1.5 & $<0.0001$ \\
\hline Nuts & 1.2 & 0.1 & 1.6 & 0.1 & $2 \cdot 1$ & 0.1 & $3 \cdot 2$ & 0.1 & $5 \cdot 7$ & 0.1 & $<0.0001$ \\
\hline Legumes & $14 \cdot 6$ & 0.6 & $14 \cdot 2$ & 0.5 & $17 \cdot 1$ & 0.6 & $20 \cdot 3$ & 0.5 & $45 \cdot 9$ & 0.5 & $<0.0001$ \\
\hline Seafood & 32.0 & 0.6 & 41.0 & 0.6 & 40.4 & 0.6 & $45 \cdot 1$ & 0.6 & $36 \cdot 3$ & 0.6 & $<0.0001$ \\
\hline Meat & $98 \cdot 1$ & 1.0 & 64.8 & 1.0 & $69 \cdot 0$ & 1.0 & $56 \cdot 6$ & 1.0 & $37 \cdot 7$ & 1.0 & $<0.0001$ \\
\hline Processed meat & 37.0 & 0.4 & 34.6 & 0.4 & $35 \cdot 3$ & 0.4 & 32.4 & 0.4 & 20.4 & 0.4 & $<0.0001$ \\
\hline Poultry & $25 \cdot 6$ & 0.4 & 27.8 & 0.4 & $27 \cdot 0$ & 0.4 & $25 \cdot 7$ & 0.4 & $15 \cdot 3$ & 0.4 & $<0.0001$ \\
\hline Eggs & $11 \cdot 1$ & 0.3 & $12 \cdot 9$ & 0.3 & 11.6 & 0.3 & 18.5 & 0.3 & 10.5 & 0.3 & 0.0027 \\
\hline Milk & $76 \cdot 3$ & 1.9 & $68 \cdot 1$ & 1.9 & $60 \cdot 6$ & 1.9 & 59.5 & 1.9 & 41.3 & 1.9 & $<0.0001$ \\
\hline Dairy products & 158.2 & 1.9 & 158.2 & 1.8 & 148.6 & 1.9 & $146 \cdot 1$ & 1.8 & $88 \cdot 2$ & 1.8 & $<0.0001$ \\
\hline Cheese & 34.8 & 0.6 & $41 . \overline{9}$ & 0.6 & 38.9 & 0.6 & $36 \cdot 3$ & 0.6 & $30 . \overline{7}$ & 0.6 & $<0.0001$ \\
\hline Milky desserts & 14.4 & 1.9 & $14 \cdot 2$ & 1.8 & $10 \cdot 9$ & 1.9 & 8.5 & 1.8 & $6 \cdot 2$ & 1.8 & $<0.0001$ \\
\hline Potatoes & $27 \cdot 8$ & 0.5 & 34.0 & 0.5 & $24 \cdot 1$ & 0.5 & 23.4 & 0.5 & 22.6 & 0.5 & $<0.0001$ \\
\hline Bread§̧ & $82 \cdot 7$ & 0.9 & 92.4 & 0.9 & $89 \cdot 2$ & 0.9 & $99 \cdot 7$ & 0.9 & $86 \cdot 0$ & 0.9 & $<0.0001$ \\
\hline Cereals\|l| & 95.5 & $1 \cdot 1$ & $97 \cdot 1$ & $1 \cdot 1$ & $88 \cdot 2$ & $1 \cdot 1$ & $88 \cdot 2$ & $1 \cdot 1$ & $83 \cdot 1$ & $1 \cdot 1$ & $<0.0001$ \\
\hline Wholegrain products $\Phi$ & $11 \cdot 1$ & 0.7 & 11.0 & 0.6 & 13.4 & 0.6 & $27 \cdot 0$ & 0.6 & 47.7 & 0.6 & $<0.0001$ \\
\hline Vegetable oil & 12.5 & 0.2 & $18 \cdot 2$ & 0.2 & $16 \cdot 2$ & 0.2 & 19.1 & 0.2 & $20 \cdot 6$ & 0.2 & $<0.0001$ \\
\hline Butter/margarine & $7 \cdot 1$ & 0.1 & 6.9 & 0.1 & $6 \cdot 3$ & 0.1 & 6.4 & 0.1 & 4.7 & 0.1 & $<0.0001$ \\
\hline Other fats ${ }^{\star \star}$ & 3.0 & 0.1 & $3 \cdot 1$ & 0.1 & 3.5 & 0.1 & 3.0 & 0.1 & 3.5 & 0.1 & $<0.0001$ \\
\hline Dressing & $8 \cdot 1$ & $0 \cdot 1$ & $7 \cdot 0$ & 0.1 & 6.8 & 0.1 & 6.5 & 0.1 & $6 \cdot 4$ & 0.1 & $<0.0001$ \\
\hline Cookies & $18 \cdot 2$ & 0.3 & $12 \cdot 3$ & 0.3 & $10 \cdot 3$ & 0.3 & $9 \cdot 0$ & 0.3 & 7.5 & 0.3 & $<0.0001$ \\
\hline Sweets†† & 47.5 & 0.5 & 43.0 & 0.5 & $47 \cdot 7$ & 0.5 & $47 \cdot 4$ & 0.5 & $46 \cdot 1$ & 0.5 & 0.95 \\
\hline Fast foods & $36 \cdot 8$ & $2 \cdot 1$ & 24.9 & 2.0 & 79.5 & $2 \cdot 1$ & $25 \cdot 1$ & 2.0 & $24 \cdot 1$ & 2.0 & $<0.0001$ \\
\hline Snacksł‡ & 9.4 & 0.2 & 7.9 & 0.2 & 9.8 & 0.2 & 8.3 & 0.2 & $13 \cdot 2$ & 0.2 & $<0.0001$ \\
\hline Grains§§ & 0.8 & 0.1 & 1.5 & 0.1 & $2 \cdot 1$ & 0.1 & 2.9 & 0.1 & 6.5 & 0.1 & $<0.0001$ \\
\hline Dairy substitutes||II & $6 \cdot 8$ & 1.4 & $7 \cdot 7$ & 1.4 & $17 \cdot 8$ & 1.4 & $39 \cdot 7$ & 1.4 & 88.1 & 1.4 & $<0.0001$ \\
\hline Meat substitutes & 1.6 & 0.3 & 3.6 & 0.3 & 3.8 & 0.3 & 9.3 & 0.3 & $21 \cdot 2$ & 0.3 & $<0.0001$ \\
\hline Non-alcoholic drinks II & 635.9 & 6.5 & 655.6 & 6.4 & 735.4 & 6.4 & 735.0 & $6 \cdot 3$ & 667.7 & $6 \cdot 3$ & $<0.0001$ \\
\hline Alcohol & $87 \cdot 1$ & $2 \cdot 0$ & 90.6 & 1.9 & $112 \cdot 4$ & 1.9 & 87.4 & 1.9 & 86.0 & 1.9 & 0.45 \\
\hline Soda & 93.0 & 1.9 & 74.0 & 1.9 & 45.5 & 1.9 & 42.4 & 1.9 & 28.6 & 1.9 & $<0.0001$ \\
\hline Water & 908.8 & 9.3 & 939.6 & $9 \cdot 1$ & 991.3 & 9.2 & 982.6 & $9 \cdot 0$ & 927.9 & $9 \cdot 0$ & $<0.0001$ \\
\hline
\end{tabular}

${ }^{*} \mathrm{Q}$, quintile.

†Values presented are means with their standard errors adjusted for sex, age and total energy intake.

$\ddagger$ Values based on linear contrast test.

§Including bread and whole bread.

IIIncluding pasta, white rice, muesli, semolina and breakfast cereals.

IIncluding wholegrain rice and wholegrain pasta.

**Including mayonnaise, fresh cream and vegetal fresh cream.

††Including jam, honey, sugar, sweeteners, confectionery, chocolate and chocolate spread bars, cakes, brownies, pancakes and ice cream.

¥¥Including chips, popcorns, salted cakes aperitif, peanuts, almonds and pistachio nuts.

$\S \S$ Including sprouted seeds, bran and wheat germs.

IIIIIncluding soya yoghurt, vegetal-based cheese, vegan fresh cheese and soya milk.

ITIncluding coffee, tea, chicory and hot chocolate.

Table 3 Diet quality scores by level of organic food consumption in the diet of French adults, NutriNet-Santé Study, $2014(n 28245)^{\star} \dagger$

\begin{tabular}{|c|c|c|c|c|c|c|c|c|c|c|c|}
\hline & \multicolumn{2}{|c|}{ Q1 (0.00-0.01) } & \multicolumn{2}{|c|}{ Q2 (0.01-0.09) } & \multicolumn{2}{|c|}{ Q3 (0.09-0.25) } & \multicolumn{2}{|c|}{ Q4 (0.25-0.49) } & \multicolumn{2}{|c|}{ Q5 $(0.49-1.00)$} & \multirow[b]{2}{*}{$P$-trend $\ddagger$} \\
\hline & Mean & $\mathrm{SE}$ & Mean & SE & Mean & SE & Mean & $\mathrm{SE}$ & Mean & SE & \\
\hline $\begin{array}{l}\text { mPNNS-GS } \\
\text { PANDiet }\end{array}$ & $\begin{array}{r}7.89 \\
63.04\end{array}$ & $\begin{array}{l}0.02 \\
0.11\end{array}$ & $\begin{array}{r}8.04 \\
64.38\end{array}$ & $\begin{array}{l}0.02 \\
0.11\end{array}$ & $\begin{array}{r}8.28 \\
64.64\end{array}$ & $\begin{array}{l}0.02 \\
0.11\end{array}$ & $\begin{array}{r}8.45 \\
65.92\end{array}$ & $\begin{array}{l}0.02 \\
0.10\end{array}$ & $\begin{array}{r}8.78 \\
69.37\end{array}$ & $\begin{array}{l}0.02 \\
0.10\end{array}$ & $\begin{array}{l}<0.0001 \\
<0.0001\end{array}$ \\
\hline
\end{tabular}

${ }^{*} \mathrm{Q}$, quintile; mPNNS-GS, modified Programme National Nutrition Santé Guidelines Score; PANDiet, probability of adequate nutrient intake. †Values presented are means with their standard errors adjusted for sex, age and total energy intake.

$\ddagger$ Values based on linear contrast test.

proportion of individuals meeting the recommendation on 'added fat' gradually decreased.

This was not the case for added fat of vegetable origin: here, the highest proportion of individuals meeting the recommendation was found in Q5. Q5 also included the highest proportion of individuals complying with the guideline on wholegrain foods. Of note, the highest proportion of individuals meeting the recommendations 
Table 4 Compliance with the individual components of the mPNNS-GS by level of organic food consumption in the diet of French adults, NutriNet-Santé Study, 2014 ( $n$ 28245) ${ }^{\star} \dagger$

\begin{tabular}{|c|c|c|c|c|c|c|}
\hline Follow the recommendation (\%) & $\begin{array}{c}\mathrm{Q} 1 \\
(0.00-0.01)\end{array}$ & $\begin{array}{c}\mathrm{Q} 2 \\
(0.01-0.09)\end{array}$ & $\begin{array}{c}\text { Q3 } \\
(0.09-0.25)\end{array}$ & $\begin{array}{c}\mathrm{Q} 4 \\
(0.25-0.49)\end{array}$ & $\begin{array}{c}\text { Q5 } \\
(0.49-1.00)\end{array}$ & $P$-trend $\ddagger$ \\
\hline Fruit and vegetables & $56 \cdot 9$ & $57 \cdot 5$ & $64 \cdot 7$ & $69 \cdot 9$ & $80 \cdot 2$ & $<0.0001$ \\
\hline $\begin{array}{l}\text { Starchy foods (bread, cereals, } \\
\text { potatoes and legumes) }\end{array}$ & $37 \cdot 7$ & $37 \cdot 9$ & $40 \cdot 6$ & 41.5 & $42 \cdot 9$ & $<0.0001$ \\
\hline Wholegrain foods & 8.5 & 13.7 & $12 \cdot 3$ & $16 \cdot 2$ & $22 \cdot 2$ & $<0.0001$ \\
\hline Dairy products & $20 \cdot 9$ & $26 \cdot 7$ & $30 \cdot 8$ & $25 \cdot 1$ & $17 \cdot 6$ & $<0.0001$ \\
\hline Meat, poultry, seafood and eggs & 43.0 & $46 \cdot 5$ & $47 \cdot 1$ & $46 \cdot 8$ & $37 \cdot 2$ & $<0.0001$ \\
\hline Seafood & $27 \cdot 7$ & $40 \cdot 5$ & $41 \cdot 3$ & $47 \cdot 8$ & $39 \cdot 1$ & $<0.0001$ \\
\hline Added fat & $82 \cdot 1$ & 74.7 & $74 \cdot 3$ & 71.7 & 68.4 & $<0.0001$ \\
\hline Added fat of vegetable origin & $91 \cdot 2$ & $89 \cdot 8$ & $90 \cdot 6$ & $90 \cdot 2$ & $95 \cdot 1$ & $<0.0001$ \\
\hline $\begin{array}{l}\text { Sweetened foods (sugar, sweets } \\
\text { and cookies) }\end{array}$ & $86 \cdot 4$ & $86 \cdot 4$ & $91 \cdot 2$ & $92 \cdot 5$ & $95 \cdot 0$ & $<0.0001$ \\
\hline Non-alcoholic beverages & $92 \cdot 4$ & $91 \cdot 4$ & $97 \cdot 0$ & $95 \cdot 8$ & $97 \cdot 7$ & $<0.0001$ \\
\hline Alcohol & $93 \cdot 1$ & 89.6 & $90 \cdot 6$ & 94.0 & 93.7 & $<0.0001$ \\
\hline Salt & $51 \cdot 3$ & $45 \cdot 3$ & $44 \cdot 2$ & $44 \cdot 1$ & $62 \cdot 8$ & $<0.0001$ \\
\hline
\end{tabular}

${ }^{*} \mathrm{Q}$, quintile; mPNNS-GS, modified Programme National Nutrition Santé Guidelines Score.

†Values presented are percentages of individuals with adequate intake.

$\ddagger$ Values based on trend $x^{2}$ test.

on animal-based products (dairy products; meat, poultry, seafood and eggs; seafood) was found in the three intermediate quintiles. Concerning non-alcoholic beverages and salt, Q5 included the highest proportion of individuals meeting the recommendations. The lowest percentage of individuals following the recommendation on alcohol was found in Q2 and the highest in Q4.

Stratified analyses according to various sociodemographic and lifestyle factors are presented in Supplemental Fig. 1 (see online supplementary material). Overall, significant positive associations were found between the nutritional quality of the diet and organic food consumption in each subgroup. The strength of the association varied across subgroups (from $\beta_{\text {current smoker }}=$ $0.53 ; 95 \%$ CI $0 \cdot 25,0 \cdot 80$ to $\beta_{\text {income } 1800-2700 €}=1 \cdot 40 ; 95 \%$ CI 1.26 , $1 \cdot 54)$.

\section{Discussion}

Our study evaluated the dietary intakes and diet quality across different levels of organic foods in the diet among a large population of French adults using detailed dietary data. A higher level of organic food consumption was related to overall healthier dietary patterns, although intermediate organic food consumers showed better adherence to nutritional recommendations related to animal product intakes.

Studies reporting sociodemographic and lifestyle differences between non-organic food consumers and frequent organic consumers are plentiful ${ }^{(6,25,30,44-49)}$ and one was conducted in the NutriNet-Santé cohort ${ }^{(28)}$. Consistent with previous studies ${ }^{(25,45,47-49)}$, we found herein that income seemed to be a weak determinant compared with education to explain differences in organic food consumption behaviours. However, whether high consumption of organic foods was not necessarily related to high household income, low consumers exhibited elevated percentages of individuals with a low income in accordance with another work $^{(49)}$.

Few studies have explored the relationship between level of organic food consumption and intake of food groups and they focused only on the frequency of consumption of organic foods (frequent/regular/ occasional $v$. non-consumption $)^{(25,26,28,30)}$. We found herein that intakes of plant-based foods increased along with an increase in the share of organic foods in the diet while the reverse was observed for most animalbased foods. Furthermore, an inverse gradient was found between consumption of cookies and soda and the proportion of organic foods in the diet. The previous $^{(25,26,28,30)}$ and present convergent observations made from different surveys lead to state that a high level of organic food consumption is combined with a diet based on healthier foods. Nevertheless, as no clear linear trend was found between organic food consumption and the intake of sweet products, it can be assumed that individuals with a high consumption of organic foods did not exclude all unhealthy products. Similarly, in a German study, men consumed comparable amounts of sweets regardless of organic foods buying frequency, although women buying organic foods ate fewer sweets ${ }^{(30)}$.

Another important finding of our study was that very high consumers of organic foods (Q5) exhibited particular dietary practices. Their intakes of nuts, legumes, wholegrain products, grains, and meat and dairy substitutes (including soya yoghurt, vegetal-based cheese, vegan fresh cheese and soya milk) were much higher than in the other groups. The consumption of dairy products in Q5 was almost half that in the other quintiles while the intake of dairy substitutes in Q5 was at least twice higher, suggesting a substitution of dairy products (animal-based foods) towards dairy substitutes (plant-based foods). This can be attributed, at least in part, to the high proportion of 
vegetarians and vegans present in this group who have high intakes of whole grains and grains ${ }^{(50)}$. Previous works have also shown strong associations between regular organic food consumption and vegetarianism ${ }^{(25,26,44)}$. The underlying motives of organic food consumption and a vegetarian or vegan diet may also be convergent ${ }^{(51)}$.

With regard to consumption of poultry, apart from Q5, the different categories of consumers seemed to have a comparable intake. Furthermore, across the five groups, individuals in Q4 had the highest intake of seafood and eggs. It seems that individuals in Q5 tended to avoid food products of animal origin including seafood or eggs, while individuals in Q4 tended to be less restrictive and might replace meat by a higher consumption of seafood and eggs. Thus, the diet of consumers in Q4 seemed to be close to a 'flexitarian diet' (i.e. an occasional consumption of meat). The underlying motives for consuming organic food products between the two groups may not be the same. This may have consequences in terms of the promotion of organic food consumption. A previous work thus showed that food choices of flexitarians were motivated by weight control or health while food choices of vegetarians were motivated by ethical concerns ${ }^{(52,53)}$.

As underlined above, intakes of animal products were much lower in Q5 compared with Q4. This resulted in lower adequacy to the recommendations pertaining to animal-based foods. However, the animal foods consumed in Q5 were largely of organic origin. Recent meta-analyses have shown differences in fatty acid composition between organic and conventional animal foods, with higher total PUFA and $n$-3 PUFA concentrations in organic milk ${ }^{(15)}$. Concerning organic meat, the evidence base is weak ${ }^{(16)}$ and studies on nutritional values of organic seafood are needed. Even though the difference at the food level is low, these 'organic' benefits may affect the nutritional status of Q5 participants at the diet level. However, composition data according to production method are lacking and thus PUFA intake has probably been underestimated in our study.

Thus, not only may the consumption patterns of high organic food consumers be linked to lower risk of chronic diseases, but also their high consumption of organic products with some potentially better nutritional profiles may lead to better health status than their counterparts, although this still needs to be documented.

Strikingly, the two diet quality scores increased from Q1 to Q5 reflecting in the latter a better compliance with the nutritional guidelines and a better nutrient status. This is explained by the more important intakes of healthy foods such as fruit and vegetables, legumes, whole grains and nuts among high organic food consumers as described above. This seems consistent with previous studies ${ }^{(26-28,30)}$ showing that frequent organic food consumers exhibit an overall better diet quality than non-organic food consumers.

Interestingly, when focusing on the individual dietary components of the mPNNS-GS, individuals with the highest proportion of organic foods in their diet (Q4 and Q5) tended to follow the nutritional recommendations pertaining to plant-based products but fewer followed animal-based products recommendations (inverted U-shaped relationships for dairy products and for meat, poultry, seafood and eggs). Thus, although the high organic food consumers had, overall, a healthier diet, the results regarding animal-based recommendations were more balanced: moderate organic food consumers seemed to include a larger variety of products of different origin in their diet. This resulted in a lower intake of vitamin $B_{12}$ among Q5 participants. Nevertheless, the overall healthier dietary patterns reflected by higher dietary scores of high organic food consumers may translate into better healthrelated outcomes as observed in some studies ${ }^{(28,54,55)}$

We also observed a positive association between increased organic food consumption in the diet and the nutritional quality of the diet whatever the sociodemographic or lifestyle category. However, the magnitude of this association was variable depending on the subgroup considered (e.g. higher among males or among participants living in an urban unit with a population of $>200000$ inhabitants). For these specific subgroups, even more than for the other groups, consumption of organic foods is probably part of an integrated approach of a global strategy towards a healthy diet.

Dietary patterns of high organic food consumers seem to fit those of sustainable diets ${ }^{(56)}$. The FAO has defined sustainable diets as those "with low environmental impacts which contribute to food and nutrition security and to healthy life for present and future generations. Sustainable diets are protective and respectful of biodiversity and ecosystems, culturally acceptable, accessible, economically fair and affordable; nutritionally adequate, safe and healthy; while optimising natural and human resources, ${ }^{\text {(1) }}$. High organic food consumers exhibited healthier dietary habits better for their own health. Besides the positive environmental impacts of organic production ${ }^{(57-59)}$, they exhibited a plant-based diet with low consumption of meat, thereby reducing life-cycle greenhouse gas emissions ${ }^{(60)}$. Other studies have shown that high organic food consumers also favoured more direct links with producers ${ }^{(61)}$. The estimation of the sustainability of an 'organic diet' should therefore encompass all these factors including sources (organic or conventional), dietary patterns and practices.

Our study presents major strengths. One of the strengths lies in its large sample size that includes 28245 French adults. It enables a large variation in dietary behaviours and in the practices about organic foods. A further strength of the current study is the use of a semi-quantitative FFQ that includes 264 items. It is also worthwhile mentioning that an innovative approach was used to assess organic food consumption using detailed data, allowing evaluation of the proportion of organic foods in the whole diet. However, the study has also several limitations. Given that the individuals enrolled were volunteers in a cohort 
focusing on nutrition and health, they were certainly particularly interested in these topics. Furthermore, filling in the questionnaire was optional; therefore individuals included in the study were also more concerned with sustainable food issues than the general population and the other participants of the cohort. This may have led to recruitment biases and caution is therefore needed when generalising the results. The use of a 5-point ordinal scale has led to an overestimation of the actual organic food consumption as, for instance, a percentage of $25 \%$ was allocated to the frequency 'rarely', not reflecting the very occasional consumers. However, in a sensitivity analysis $^{(37)}$, we attributed a percentage of $10 \%$ to the frequency 'rarely' and the results were not substantially modified. FFQ have also been shown to misestimate overall food intake and in turn this must have been the case for organic food intake. Data collection was based on self-administered questionnaires which are prone to measurement errors. However, the Org-FFQ was based on a validated FFQ which had shown relative validity and reproducibility ${ }^{(36)}$. Finally, composition tables are based on average values and do not take into account the type of farming (conventional or organic). Recent meta-analyses $^{(14,15)}$ have reported higher antioxidant concentrations in organic crops as well as higher PUFA and $n$-3 PUFA, conjugated linoleic acid, $\alpha$-tocopherol and $\mathrm{Fe}$, but lower iodine and Se concentrations in organic milk. The potential differences between the observed intakes must be therefore interpreted in the light of this limitation. Development of updated food composition databases accounting for farming practices seems necessary to accurately estimate nutrient intakes of high organic food $v$. non-organic consumers.

\section{Conclusion}

In conclusion, the present study provides new insights into the understanding of organic food consumption as an integral part of a healthy diet. These findings underline strong dietary behaviour correlates associated with organic food consumption that should be taken into account and controlled for in future aetiological studies on organic food consumption and health. Furthermore, an organic-based diet seemed to coincide with a plant-based diet and therefore might better fit the sustainable diet definition. In a framework of sustainable diet development, a better characterisation of organic food consumers including their motivations and trajectories in various contexts, as well as the sustainability of the 'organic diet', is needed.

\section{Acknowledgements}

Acknowledgements: The authors thank all the people who helped carry out the NutriNet-Santé Study and all dedicated and conscientious volunteers. They especially thank Younes Esseddik, Mohand Ait-Oufella, Paul Flanzy, Yasmina Chelghoum, Véronique Gourlet, Nathalie Arnault, Fabien Szabo, Laurent Bourhis, Charlotte Voetglin and Cédric Agaesse. Financial support: The BioNutriNet project was supported by the French National Research Agency (Agence Nationale de la Recherche) in the context of the 2013 Programme de Recherche Systèmes Alimentaires Durables (ANR-13-ALID-0001). The NutriNet-Santé cohort study is funded by the following public institutions: Ministère de la Santé, Institut de Veille Sanitaire (InVS), Institut National de la Prévention et de l'Education pour la Santé (INPES), Institut National de la Santé et de la Recherche Médicale (INSERM), Institut National de la Recherche Agronomique (INRA), Conservatoire National des Arts et Métiers (CNAM) and Paris 13 University. The funders had no role in study design, data collection and analysis, decision to publish, or preparation of the manuscript. Conflict of interest: None. Authorship: The authors' contributions were as follows. Conceived and designed the experiments: S.H., P.G., E.K.-G., S.P., C.M., M.T. and D.L. Performed the experiments: J.B., S.H., P.G., E.K.-G., S.P., C.M. and M.T. Analysed the data: J.B. Wrote the paper: J.B. and E.K.-G. Involved in interpreting results and editing the manuscript: J.B., B.A., S.P., M.T., C.M., S.H., P.G., D.L. and E.K.-G. J.B. had primary responsibility for final content. All authors read and approved the final manuscript. Ethics of buman subject participation: The NutriNet-Santé Study was conducted according to guidelines laid down in the Declaration of Helsinki and was approved by the Institutional Review Board of the French Institute for Health and Medical Research (IRB Inserm number 0000388FWA00005831) and the 'Comité National Informatique et Liberté' (CNIL numbers 908450 and 909216). Electronic informed consent was obtained from all participants (EudraCT number 2013-000929-31).

\section{Supplementary material}

To view supplementary material for this article, please visit http://dx.doi.org/10.1017/S1368980016002718

\section{References}

1. Burlingame B \& Dernini S (editors) (2012) Sustainable Diets and Biodiversity - Directions and Solutions for Policy Research and Action, Proceedings of the International Scientific Symposium Biodiversity and Sustainable Diets United Against Hunger, 3-5 November 2010, FAO Headquarters, Rome. Rome: FAO.

2. Strassner C, Cavoski I, Di Cagno R et al. (2015) How the organic food system supports sustainable diets and translates these into practice. Front Nutr 2, 19.

3. Willer H \& Lernoud J (2015) The World of Organic Agriculture. Statistics and Emerging Trends 2015, FiBL-IFOAM Report. Frick/Bonn: Research Institute of Organic Agriculture (FiBL)/IFOAM - Organics International.

4. Agence Bio CSA (2015) Baromètre de consommation et de perception des produits biologiques en France (Barometer of consumption of organic products in France). http:// www.agencebio.org/sites/default/files/upload/documents/ 
4_Chiffres/BarometreConso/barometre_agence_bio_public.pdf (accessed May 2015).

5. Magnusson MK, Arvola A, Hursti U-KK et al. (2003) Choice of organic foods is related to perceived consequences for human health and to environmentally friendly behaviour. Appetite 40, 109-117.

6. Hughner RS, McDonagh P, Prothero A et al. (2007) Who are organic food consumers? A compilation and review of why people purchase organic food. J Consum Behav $\mathbf{6}$, 94-110.

7. Michaelidou N \& Hassan LM (2008) The role of health consciousness, food safety concern and ethical identity on attitudes and intentions towards organic food. Int J Consum Stud 32, 163-170.

8. Aertsens J, Verbeke W, Mondelaers K et al. (2009) Personal determinants of organic food consumption: a review. $\mathrm{Br}$ Food J 111, 1140-1167.

9. Hoefkens C, Verbeke W, Aertsens J et al. (2009) The nutritional and toxicological value of organic vegetables: consumer perception versus scientific evidence. Br Food J 111, 1062-1077.

10. Grunert KG (2005) Food quality and safety: consumer perception and demand. Eur Rev Agric Econ 32, 369-391.

11. Johansson E, Hussain A, Kuktaite R et al. (2014) Contribution of organically grown crops to human health. Int J Environ Res Public Health 11, 3870-3893.

12. Lairon D \& Huber M (2014) Food quality and possible positive health effects of organic products. In Organic Farming, Prototype for Sustainable Agricultures, pp. 295-312 [S Bellon and S Penvern, editors]. Dordrecht: Springer.

13. Rembiałkowska E (2007) Quality of plant products from organic agriculture. J Sci Food Agric 87, 2757-2762.

14. Barański M, Średnicka-Tober D, Volakakis N et al. (2014) Higher antioxidant and lower cadmium concentrations and lower incidence of pesticide residues in organically grown crops: a systematic literature review and meta-analyses. Br J Nutr 112, 794-811.

15. Średnicka-Tober D, Barański M, Seal CJ et al. (2016) Higher PUFA and $n$ - 3 PUFA, conjugated linoleic acid, $\alpha$-tocopherol and iron, but lower iodine and selenium concentrations in organic milk: a systematic literature review and meta- and redundancy analyses. Br J Nutr 115, 1043-1060.

16. Średnicka-Tober D, Barański M, Seal C et al. (2016) Composition differences between organic and conventional meat: a systematic literature review and meta-analysis. Br J Nutr 115, 994-1011.

17. Kummeling I, Thijs C, Huber M et al. (2008) Consumption of organic foods and risk of atopic disease during the first 2 years of life in the Netherlands. Br J Nutr 99, 598-605.

18. Rist L, Mueller A, Barthel C et al. (2007) Influence of organic diet on the amount of conjugated linoleic acids in breast milk of lactating women in the Netherlands. Br J Nutr 97, 735-743.

19. Oates L, Cohen M, Braun L et al. (2014) Reduction in urinary organophosphate pesticide metabolites in adults after a week-long organic diet. Environ Res 132, 105-111.

20. Curl CL, Fenske RA \& Elgethun K (2002) Organophosphorus pesticide exposure of urban and suburban preschool children with organic and conventional diets. Environ Health Perspect 111, 377-382.

21. Curl CL, Beresford SAA, Fenske RA et al. (2015) Estimating pesticide exposure from dietary intake and organic food choices: the Multi-Ethnic Study of Atherosclerosis (MESA). Environ Health Perspect 123, 475-483.

22. Bradbury KE, Balkwill A, Spencer EA et al. (2014) Organic food consumption and the incidence of cancer in a large prospective study of women in the United Kingdom. Br J Cancer 110, 2321-2326.

23. Torjusen H, Brantsæeter AL, Haugen M et al. (2014) Reduced risk of pre-eclampsia with organic vegetable consumption: results from the prospective Norwegian Mother and Child Cohort Study. BMJ Open 4, e006143.

24. Goetzke B, Nitzko S \& Spiller A (2014) Consumption of organic and functional food. A matter of well-being and health? Appetite 77, 94-103.

25. Petersen SB, Rasmussen MA, Strøm M et al. (2013) Sociodemographic characteristics and food habits of organic consumers - a study from the Danish National Birth Cohort. Public Health Nutr 16, 1810-1819.

26. Torjusen H, Lieblein G, Naes T et al. (2012) Food patterns and dietary quality associated with organic food consumption during pregnancy; data from a large cohort of pregnant women in Norway. BMC Public Health 12, 612.

27. Pelletier JE, Laska MN, Neumark-Sztainer D et al. (2013) Positive attitudes toward organic, local, and sustainable foods are associated with higher dietary quality among young adults. J Acad Nutr Diet 113, 127-132.

28. Kesse-Guyot E, Péneau S, Méjean C et al. (2013) Profiles of organic food consumers in a large sample of French adults: results from the Nutrinet-Santé Cohort Study. PLOS ONE $\mathbf{8}$, e76998.

29. Oates L, Cohen M \& Braun L (2012) Characteristics and consumption patterns of Australian organic consumers. J Sci Food Agric 92, 2782-2787.

30. Eisinger-Watzl M, Wittig F, Heuer T et al. (2015) Customers purchasing organic food - do they live healthier? Results of the German National Nutrition Survey II. Eur J Nutr Food Saf 5, 59-71.

31. Hercberg S, Castetbon K, Czernichow S et al. (2010) The Nutrinet-Santé Study: a web-based prospective study on the relationship between nutrition and health and determinants of dietary patterns and nutritional status. BMC Public Health 10, 242.

32. Hagströmer M, Oja P \& Sjöström M (2006) The International Physical Activity Questionnaire (IPAQ): a study of concurrent and construct validity. Public Health Nutr 9, 755-762.

33. Vergnaud A-C, Touvier M, Méjean C et al. (2011) Agreement between web-based and paper versions of a sociodemographic questionnaire in the NutriNet-Santé study. Int J Public Health 56, 407-417.

34. Touvier M, Méjean C, Kesse-Guyot E et al. (2010) Comparison between web-based and paper versions of a self-administered anthropometric questionnaire. Eur J Epidemiol 25, 287-296.

35. Insee - Institut National de la Statistique et des Etudes Economiques (2015) Definitions, methods and quality. http://www.insee.fr/en/methodes/ (accessed February 2015).

36. Kesse-Guyot E, Castetbon K, Touvier M et al. (2010) Relative validity and reproducibility of a food frequency questionnaire designed for French adults. Ann Nutr Metab 57, 153-162.

37. Baudry J, Méjean C, Allès B et al. (2015) Contribution of organic food to the diet in a large sample of French adults (the NutriNet-Santé Cohort Study). Nutrients 7, $8615-8632$.

38. Le Moullec N, Deheeger M, Preziosi P et al. (1996) Validation du manuel-photos utilisé pour l'enquête alimentaire de l'étude SU.VI.MAX. Cab Nutr Diet 31, 158-164.

39. Etude Nutrinet-Santé (2013) Table de composition des aliments de l'étude Nutrinet-Santé (Nutrinet-Santé Study Food Composition Database). Paris: Economica.

40. Estaquio C, Kesse-Guyot E, Deschamps V et al. (2009) Adherence to the French Programme National Nutrition Santé Guideline Score is associated with better nutrient intake and nutritional status. J Am Diet Assoc 109, 1031-1041.

41. Verger EO, Mariotti F, Holmes BA et al. (2012) Evaluation of a diet quality index based on the probability of adequate nutrient intake (PANDiet) using national French and US dietary surveys. PLOS ONE 7, e42155. 
42. Insee - Institut National de la Statistique et des Etudes Economiques (2015) Définitions et méthodes - La macro SAS CALMAR. http://www.insee.fr/fr/methodes/default. asp?page $=$ outils/calmar/accueil_calmar.htm (accessed July 2015).

43. Schofield WN (1985) Predicting basal metabolic rate, new standards and review of previous work. Hum Nutr Clin Nutr 39, Suppl. 1, 5-41.

44. Schifferstein HNJ \& Oude Ophuis PAM (1998) Health-related determinants of organic food consumption in The Netherlands. Food Qual Prefer 9, 119-133.

45. Yiridoe EK, Bonti-Ankomah S \& Martin RC (2005) Comparison of consumer perceptions and preference toward organic versus conventionally produced foods: a review and update of the literature. Renew Agric Food Syst 20, 193-205.

46. Dettmann RL \& Dimitri C (2009) Who's buying organic vegetables? Demographic characteristics of US consumers. J Food Prod Mark 16, 79-91.

47. Hassan D, Monier-Dilhan S, Nichele V et al. (2009) Organic food consumption patterns in France. I Agric Food Ind Organ 7, 1-23.

48. Torjusen H, Brantsæeter AL, Haugen M et al. (2010) Characteristics associated with organic food consumption during pregnancy; data from a large cohort of pregnant women in Norway. BMC Public Health 10, 775.

49. Pearson D, Henryks J, Sultan P et al. (2013) Organic food: exploring purchase frequency to explain consumer behavior. J Org Syst 8, 50-63.

50. Juan W, Yamini S \& Britten P (2015) Food intake patterns of self-identified vegetarians among the US population, 2007-2010. Procedia Food Sci 4, 86-93.

51. Pirjo Honkanen BV (2006) Ethical values and motives driving organic food choice. J Consum Behav 5, 420-430.

52. De Backer CJS \& Hudders L (2014) From meatless Mondays to meatless Sundays: motivations for meat reduction among vegetarians and semi-vegetarians who mildly or significantly reduce their meat intake. Ecol Food Nutr $\mathbf{5 3}$, 639-657.

53. Forestell CA, Spaeth AM \& Kane SA (2012) To eat or not to eat red meat. A closer look at the relationship between restrained eating and vegetarianism in college females. Appetite 58, 319-325.

54. Kesse-Guyot E, Touvier M, Henegar A et al. (2011) Higher adherence to French dietary guidelines and chronic diseases in the prospective SU.VI.MAX cohort. Eur J Clin Nutr 65 , 887-894.

55. Kesse-Guyot E, Castetbon K, Estaquio C et al. (2009) Association between the French nutritional guideline-based score and 6-year anthropometric changes in a French middle-aged adult cohort. Am J Epidemiol 170, 757-765.

56. Food and Agriculture Organization of the United Nations (2015) Assessing Sustainable Diets within the Sustainability of Food Systems. http://www.fao.org/publications/card/en/c/ e7ca2e1b-dd6f-4709-b582-5f10594e84cd (accessed September 2015).

57. Tuomisto HL, Hodge ID, Riordan P et al. (2012) Does organic farming reduce environmental impacts? - a meta-analysis of European research. J Environ Manage 112, 309-320.

58. Gomiero T, Pimentel D \& Paoletti MG (2011) Environmental impact of different agricultural management practices: conventional vs. organic agriculture. Crit Rev Plant Sci 30, 95-124.

59. Mondelaers K, Aertsens J \& Van Huylenbroeck G (2009) A meta-analysis of the differences in environmental impacts between organic and conventional farming. Br Food J 111, 1098-1119.

60. Tilman D \& Clark M (2014) Global diets link environmental sustainability and human health. Nature 515, 518-522.

61. Lockie S, Lyons K, Lawrence G et al. (2002) Eating 'green': motivations behind organic food consumption in Australia. Sociol Rural 42, 23-40. 